\title{
Genomic Analysis of Propane Metabolism in Methyl Tert-Butyl Ether-Degrading Mycobacterium Sp. Strain ENV421
}

\author{
Peter Robert Tupa, Hisako Masuda ${ }^{凶}$ \\ School of Sciences, Indiana University Kokomo, Kokomo, Indiana, 46902, United States of America \\ $\bowtie$ Corresponding author: email address: masudah@iuk.edu \\ (C) Ivyspring International Publisher. This is an open access article distributed under the terms of the Creative Commons Attribution (CC BY-NC) license \\ (https://creativecommons.org/licenses/by-nc/4.0/). See http://ivyspring.com/terms for full terms and conditions.
}

Received: 2018.01.14; Accepted: 2018.02.21; Published: 2018.03.02

\begin{abstract}
Methyl tert-butyl ether (MTBE) is a ground water contaminant with plausible carcinogenic properties. Mycobacterium sp. strain ENV421 cometabolically degrades MTBE and other ethers during the growth on propane as a carbon source. In this study, the $6.2 \mathrm{Mb}$ genome of strain ENV421 was deciphered. The genome sequence revealed the presence of numerous putative propane catabolic genes including genes encoding hydrocarbon oxygenases and short chain alcohol dehydrogenases. These data provide the basis for the elucidation of propane metabolic pathways in strain ENV421 and its application for the remediation of ground water contaminated with toxic ethers.
\end{abstract}

Key words: Propane, MTBE, whole genome, oxygenase, Mycobacterium, ENV421

\section{Introduction}

Propane is a gaseous three-carbon $\left(\mathrm{C}_{3}\right)$ alkane. Many bacteria have been isolated for their ability to grow on propane as a sole source of carbon and energy [1-4]. Growth on propane often supports cometabolism of many xenobiotics, including trichloroethylene, tert-butyl ether, ethyl tert-butyl ether, tert-amyl methyl ether, $N$-nitrosodimethylamine (NDMA) and 1, 4-dioxane [1, 2, 5-7]. Propane oxygenases, enzymes responsible for the initial oxidation step of the propane metabolic pathway, are postulated to be responsible for the cometabolic removal of pollutants $[2,7]$. Thus, the identification of propane-inducible genes, in particular the propane oxygenases, is of interest for understanding not only the metabolic pathway of propane but also the basis behind the catabolic versatility of propane-grown cells and their application in the remediation of environmental pollutants.

The initial rate-limiting step of aerobic alkane metabolism is hydroxylation using molecular oxygen and NADH [8, 9]. There are numerous articles investigating enzymes responsible for hydroxylation of methane $\left(C_{1}\right)$ and liquid alkanes $\left(C_{5}-C_{16}\right)$ [10-13]. Methanotrophs utilize soluble methane monooxygenase (sMMO), belonging to the soluble diiron monooxygenase (SDIMO) family, and/or particulate methane monooxygenase (pMMO) for the initial oxidation of methane [10,14, 15]. Oxidation of liquid linear alkanes are catalyzed by membrane-bound non-heme diiron alkane monooxygenase (AlkB) or cytochrome P450 CYP153, thereby forming alkyl alcohol [11, 12].

The involvement of methane and liquid alkane oxygenases in propane oxidation has been detected $[6$, 16-18]. Heterologously expressed or partially purified sMMO and pMMO have been shown to oxidize propane [16, 18]. While the substrate range of AlkB and CYP153 are typically limited to medium chain alkanes, in vivo evolution enabled them to oxidize propane [19]. Recently, homologues of sMMO were found in propanotroph, and named propane monooxygenase (Prm) [3, 4, 6]. Genetic knockout of a 
Prm-encoding gene in Rhodococcus sp. strain RHA1, Mycobacterium smegmatis MC2155 strain, and Gordonia sp. strain TY-5 abolished their growth on propane [4, $6,20]$.

Oxygenases hydroxylate propane at the terminal and/or the sub-terminal position, producing 1-propanol or 2-propanol, respectively [16]. SDIMO oxidizes propane both terminally and sub-terminally, producing a mixture of 1-propanol and 2-propanol, while hydroxylation by pMMO only produces 2-propanol [16]. The 1-propanol and 2-propanols are further oxidized by dehydrogenases, converted into propanoate and acetone, respectively, before their carbons are mineralized through central metabolism $[3,21,22]$.

A link between the hydrocarbon-oxygenases and the oxidation of environmental contaminants has been documented [23, 24]. In Pseudonocardia sp. ENV478, the reduced expression of SDIMO (tetrahydrofuran monooxygenase) lowered the rate of degradation of 1, 4-dioxane [23]. E. coli heterologously expressing toluene-2 $\mathrm{MO}$, toluene- $p-\mathrm{MO}$, toluene-4$\mathrm{MO}$, propane $\mathrm{MO}$, or tetrahydrofuran $\mathrm{MO}$ have exhibited 1,4-dioxane oxidizing activity [24]. A SDIMO knockout mutant of Rhodococcus sp. strain RHA1 lost its ability to oxidize NDMA [6].

Mycobacterium strain ENV421 was isolated from a propane-enrichment culture and was shown to cometabolically degrade methyl tert-butyl ether (MTBE) [1]. Our earlier PCR-based screening revealed the presence of three oxygenase-encoding genes, namely SDIMO, cytochrome P450 genes, and alkB in ENV421 [25]. Reverse transcriptase-PCR has revealed that all three genes were expressed when grown on propane as a sole source of carbon, but not in succinate-grown cells [25]. Despite their propaneinducible expression pattern, their involvement in propane metabolism remains unknown. ENV421's CYP153, PMO and AlkB were individually cloned and expressed in E. coli host [25]. While E. coli cell lysates containing ENV421-AlkB or CYP153 exhibited octane $\left(\mathrm{C}_{8}\right)$-oxidizing activity, none of the lysates oxidized propane [25].

In this study, the genome sequence of ENV421 was determined with the intention of discovering additional hydrocarbon oxygenase-encoding genes and to further gain a comprehensive understanding of its catalytic versatility. We discovered the presence of genes encoding $\mathrm{pMMO}$ subunits, additional sMMO genes and several alcohol and aldehyde dehydrogenase genes. Comparison of the genome sequence of ENV421 and another propanotroph, Mycobacterium chubuense strain NBB4, revealed that two genomes commonly carry multiple genes encoding putative hydrocarbon oxygenases (such as SDIMO, CYP153, pMMO, and AlkB). However, the percent identity of protein sequences of each pair of oxygenases varied significantly, suggesting two genomes independently increased the repertoire of hydrocarbon oxygenaseencoding genes, mainly via multiple horizontal gene transfer events.

\section{Results and Discussions}

\section{De novo assembly of whole genome}

Genomic DNA was purified as described before [25]. A total of 25,733,000 paired-end reads were obtained by Illumina HiSeq 2500. The sequence was assembled using Velvet, yielding 169 contigs with a $\mathrm{N}_{50}$ of 153,052 (Table 1). The total size of the genome was estimated to be $6.2 \mathrm{Mb}$. The genome was annotated by NCBI Prokaryotic Annotation Pipeline. Functional annotation and classification was performed by RAST annotation server [26]. 6,075 genes with 6,024 open reading frames, 48 tRNAs and 3 rRNAs were identified. The draft genome has been deposited to the GenBank under the accession number PDHO00000000.

The $16 \mathrm{~S}$ ribosomal RNA (rRNA) sequence of strain ENV421 has shown to have high similarity to many environmental Mycobacterium strains (Figure 1). In particular, it exhibited a high sequence identity to known propanotrophs, M. sp. TY-6, M. chubuense NBB4 and NBB3, and M. sp. PH-06.

ENV421 exhibited a high sequence similarity of the 16S rRNA gene with these propanotrophs, however a comparison of the majority of the genome showed only a $20 \%$ or less sequence identity at the nucleotide level.

\section{Sequence analysis of putative hydrocarbon hydroxylase genes}

Many hydrocarbon oxygenase-encoding genes were identified in the ENV421 genome (Table 2). In addition to the three oxygenases discovered in earlier studies, several additional genes encoding hydrocarbon oxygenase subunits were identified. A total of three SDIMO loci are present in the ENV421 genome. Two CYP153 cytochrome P450 hydroxylases with more than a 53\% identity to alkane-oxidizing CYP153 from Mycobacterium sp. HXN-1500 [12], as well as forty eight additional cytochrome P450 oxygenases were discovered. Two sets of operons for AlkB complex and a locus encoding particulate methane monooxygenase (pMMO) with its corresponding electron transferring subunits were also present. 


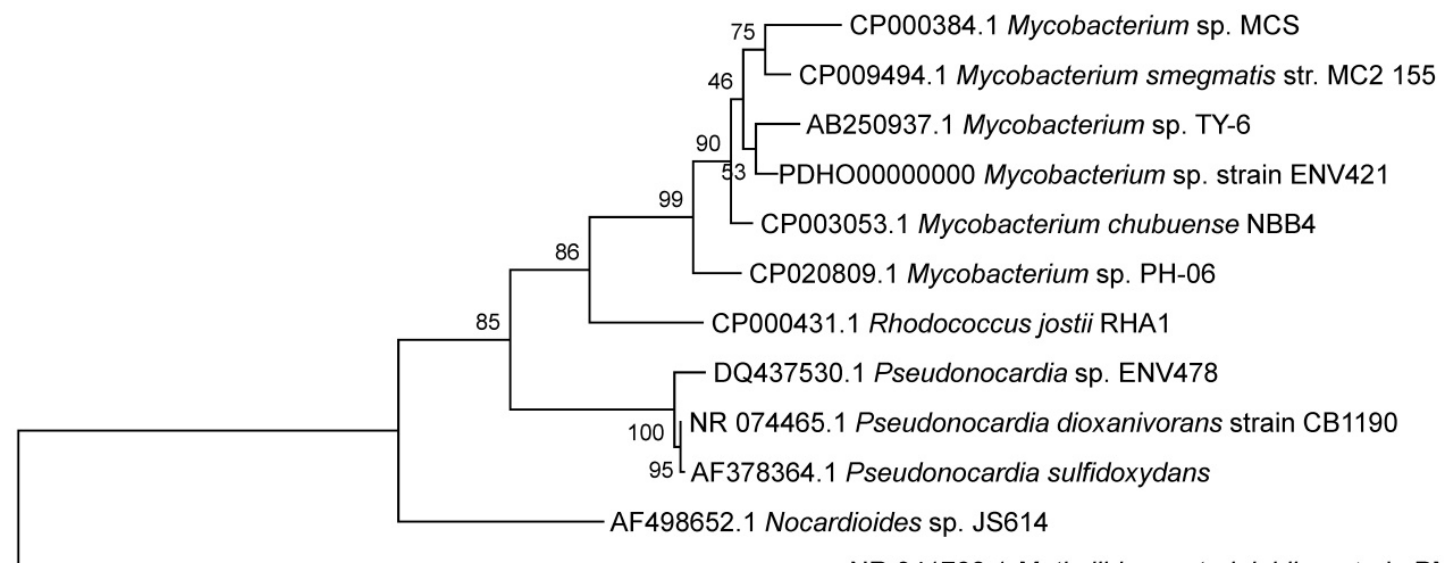

NR 041768.1 Methylibium petroleiphilum strain PM1

0.05

Figure 1. Phylogenetic tree of $16 \mathrm{~S}$ rRNA sequence

Mycobacterium sp. ENV421 CRM90_29005

Mycobacterium sp. ENV421 CRM90_28910

Mycobacterium sp. ENV421 CRM90_28385
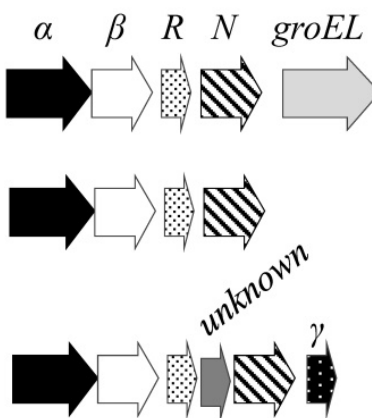

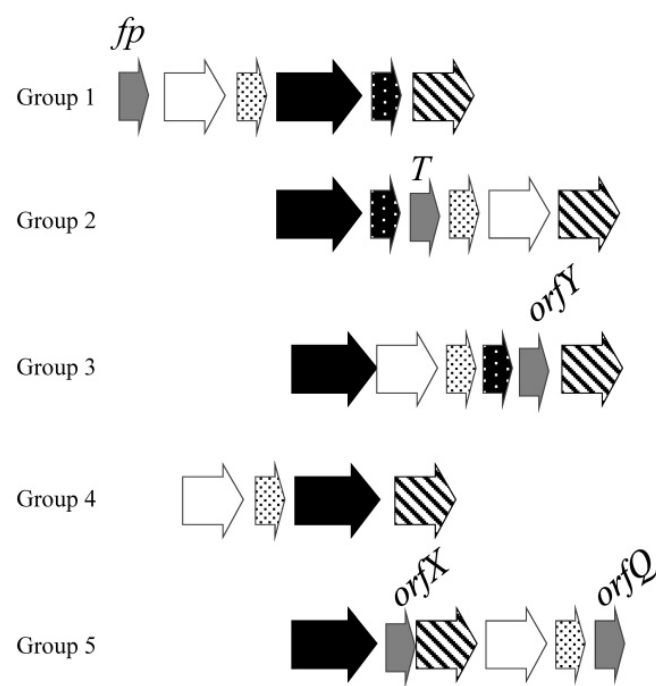

Figure 2. Gene order of SDIMO operons. Abbreviations and gene order of groups 1-5 are adopted from Notomista et al., 2003.

Table 1. Genomic features of Mycobacterium sp. strain ENV421.

\begin{tabular}{ll}
\hline Features & \\
\hline Total length (bp) & $6,228,710$ \\
N50 & 153,052 \\
GC content (\%) & 66.7 \\
Total number of genes & 6,075 \\
Protein coding gene (CDS) & 6,024 \\
rRNA genes & 48 \\
tRNA genes & 3 \\
\hline
\end{tabular}

All three SDIMO genes in ENV421 formed an operon consisting of a core of four subunits with identical gene order $(\alpha, \beta$, coupling protein and reductase) (Figure 2). One operon with CRM90_29005 contained a chaperone encoding gene, while another operon containing CRM90_28910 included two additional orfs, one encoding protein with an unknown function and another encoding $\gamma$-subunit. The gene order of four SDIMO subunits is distinctive from any of the SDIMO sub-types, classified by Notomista and colleagues (Group 1-5 in Figure 2) [27].

The phylogenetic tree of the SDIMO a-subunit shows that all three SDIMO in ENV421 form a cluster, distinctively different from groups 3 and 4 (Figure 3). The gene order of the close homologues of ENV421's SDIMO from $M$. chubuense NBB4, M. PH-06, $M$. marium E11, M. forticum, M. lenti and M. sp. TY-6 were also identical to that of ENV421 SDIMO operons, suggesting that these sequences comprise a new subgroup of SDIMO.

It is interesting to note that despite ENV421 and one of the closest propanotrophs, M. chubuense NBB4, only having on average less than $40 \%$ sequence identity at nucleotide level, their genomic regions 
containing oxygenases (e.g. CRM90_29005 and CRM90_29545) exhibited much a higher sequence identity $(>90 \%)$. Similarly, despite a relatively low phylogenetic distance between ENV421 and Gordonia amicalis $(94 \%$ in $16 \mathrm{~S}$ rRNA identity), the region containing the alkB gene cluster (CRM90_29325) shared a much higher similarity (99.5\%). These data suggest that oxygenase-encoding genes in ENV421 were acquired recently from various organisms via horizontal gene transfer.

Table 2. Hydrocarbon oxygenases in Mycobacterium sp. strain ENV421, homologues in M. chubuense strain NBB4 and other bacteria.

\begin{tabular}{|c|c|c|c|c|c|c|c|}
\hline \multirow[b]{2}{*}{ Family } & \multirow{2}{*}{$\begin{array}{l}\text { M. strain EN421 } \\
\text { Gene ID }\end{array}$} & \multicolumn{3}{|c|}{ Homologues in $M$. chubuense strain NBB4 } & \multicolumn{3}{|l|}{ Closest homologues ( $\%$ aa identity) } \\
\hline & & Gene ID & Location & $\%$ aa identity & Organism & Gene ID & $\begin{array}{l}\% \text { aa } \\
\text { identity }\end{array}$ \\
\hline \multirow[t]{3}{*}{ SDIMO } & CRM90_29005 & WP_014805366.1 & Plasmid 1 & $97 \%$ & M. chubuense NBB4 & WP_014805366.1 & $97 \%$ \\
\hline & CRM90_28385 & WP_014805366.1 & Plasmid 1 & $59 \%$ & M. fortuitum & WP_064914592.1 & $94 \%$ \\
\hline & CRM90_28910 & WP_014805752.1 & Plasmid 1 & $83 \%$ & M. chubuense NBB4 & WP_014805752.1 & $83 \%$ \\
\hline pMMO & CRM90_28135 & WP_014805761.1 & Plasmid 1 & $91 \%$ & M. chubuense NBB4 & WP_014805761.1 & $91 \%$ \\
\hline \multirow[t]{2}{*}{ CYP153 } & CRM90_29545 & WP_014805718.1 & Plasmid 1 & $98 \%$ & M. austroafricanum & WP_036374606.1 & $99 \%$ \\
\hline & CRM90_29325 & WP_014805718.1 & Plasmid 1 & $52 \%$ & G. amicalis & WP_006438771.1 & $99 \%$ \\
\hline \multirow[t]{2}{*}{ alkB } & CRM90_19665 & WP_041781781.1 & Chromosome & $75 \%$ & M. aromaticivorans JS19b1 = JCM 16368 & WP_005140454.1 & $98 \%$ \\
\hline & CRM90_27290 & WP_014816021.1 & Chromosome & $26 \%$ & M. muсоgenicum & WP_082762013.1 & $90 \%$ \\
\hline
\end{tabular}

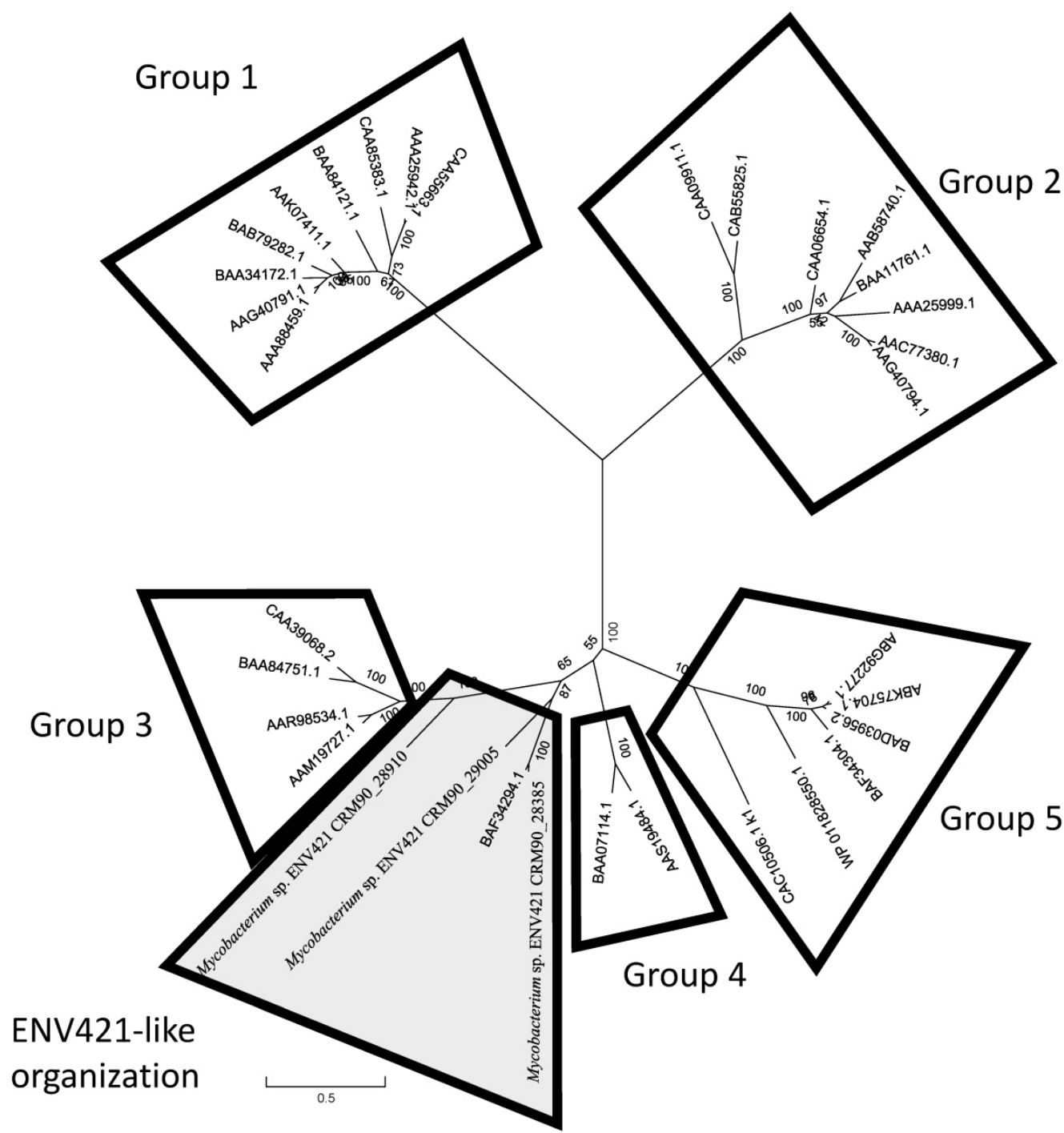

Figure 3. Phylogenetic tree of the $\alpha$ subunit of SDIMO. Groups 1-5, as described in Fig. 2, are diagrammatically shown in boxed regions. The set of sequences with an identical gene order as ENV421 SDIMOs are indicated with a shaded-boxed region. 


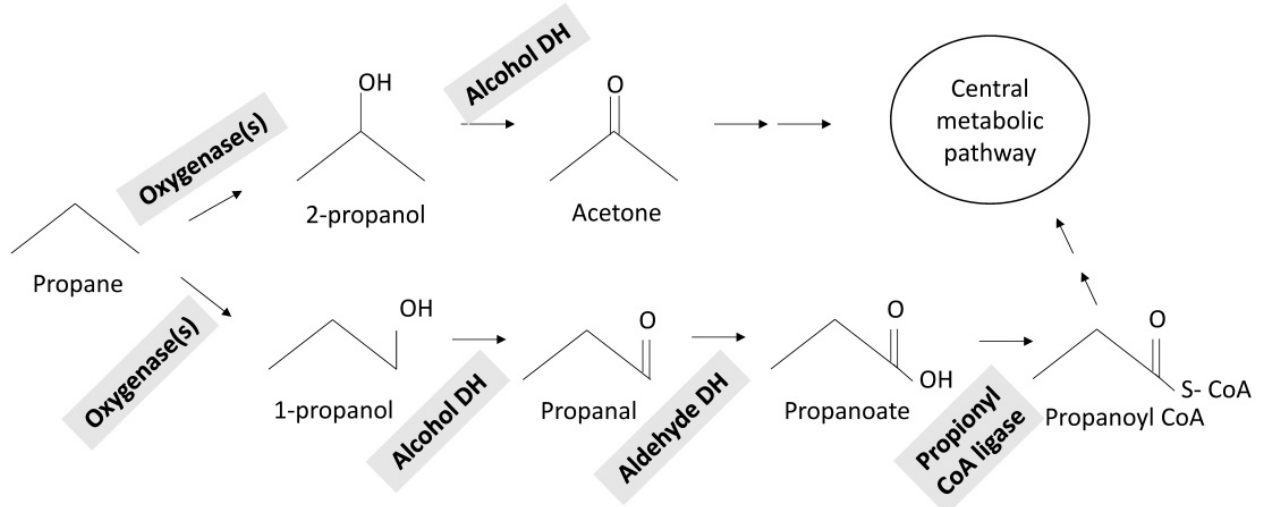

Figure 4. Proposed propane metabolic pathways in Mycobacterium sp. strain ENV421

\section{Predicted propane metabolic pathway in ENV421}

Our previous study showed that the expression of genes encoding for SDIMO, AlkB and CYP153 genes were upregulated by propane in ENV421 [25]. If SDIMO is responsible for propane metabolism in ENV421, both the terminal and the sub-terminal oxidation of propane would occur, forming 1-propanol and 2-propanol. In agreement with this idea, ENV421 is capable of growing on 1-propanol as a sole source of carbon [1]. Subsequent oxidation by alcohol and aldehyde dehydrogenases would produce propanoate, which would be further metabolized via the methylmalonyl-succinate pathway [22]. The presence of many short fatty acid CoA ligases, propionyl-CoA carboxylases (CRM90_ 03095, CRM90_05925), and methylmalonyl CoA mutases (CRM90_15015, CRM90_15020) in the genome supports this notion.

Although growth on 2-propanol was not detected, ENV421 can grow on acetone, the oxidation product of 2-propanol by alcohol dehydrogenase, as a sole source of carbon (unpublished data, Masuda). The genome sequence revealed the presence of pMMO, which exclusively produces 2-propanol upon the oxidation of propane [18]. These data suggest the possibility that propane is metabolized to 2-propanol and then to acetone. There are three acetone metabolic pathways that have been discovered in bacteria. In Xanthobacter strain Py2, acetone carboxylase converts acetone to acetoacetate [28]. In contrast, acetone was shown to be converted to methyl acetate by acetone MO in M. strain TY-5 [29]. The step wise oxidation of acetone to acetol, methy glyoxal, then to pyruvate has been proposed in strain JOB-5 [30]. The genome of ENV421 contains homologues of acetone MO (CRM90_22685) which shares a 43\% sequence identity to that of strain TY-5, while it lacks a homologue of acetone carboxylase, suggesting that strain ENV421 may oxidize acetone via a pathway similar to that of strain TY-5. Further biochemical research will be needed to fully elucidate the propane metabolic pathway in ENV421.

\section{Conclusion}

Multiple putative hydrocarbon oxygenaseencoding genes were identified in strain ENV421. The genome contained many catabolic genes, providing a genetic basis for the versatility of propane-metabolizing bacteria. Their direct involvement in the oxidation of propane and ethers will be tested in future studies.

\section{Competing Interests}

The authors have declared that no competing interest exists.

\section{References}

1. Steffan RJ, McClay K, Vainberg S, Condee CW, Zhang D. Biodegradation of the gasoline oxygenates methyl tert-butyl ether, ethyl tert-butyl ether, and tert-amyl methyl ether by propane-oxidizing bacteria. Applied and environmental microbiology. 1997; 63: 4216-22.

2. Wackett LP, Brusseau GA, Householder SR, Hanson RS. Survey of microbial oxygenases: trichloroethylene degradation by propane-oxidizing bacteria. Applied and environmental microbiology. 1989; 55: 2960-4.

3. Kotani T, Kawashima Y, Yurimoto H, Kato N, Sakai Y. Gene structure and regulation of alkane monooxygenases in propane-utilizing Mycobacterium $\mathrm{sp}$. TY-6 and Pseudonocardia sp. TY-7. Journal of bioscience and bioengineering. 2006; 102: 184-92.

4. Kotani T, Yamamoto T, Yurimoto H, Sakai Y, Kato N. Propane monooxygenase and $\mathrm{NAD}^{+}$-dependent secondary alcohol dehydrogenase in propane metabolism by Gordonia sp. strain TY-5. Journal of bacteriology. 2003; 185: $7120-8$

5. Bernhardt D, Diekmann H. Degradation of dioxane, tetrahydrofuran and other cyclic ethers by an environmental Rhodococcus strain. Applied microbiology and biotechnology. 1991; 36: 120-3.

6. Sharp JO, Sales CM, LeBlanc JC, Liu J, Wood TK, Eltis LD, et al. An inducible propane monooxygenase is responsible for $\mathrm{N}$-nitrosodimethylamine degradation by Rhodococcus sp. strain RHA1. Applied and environmental microbiology. 2007; 73: 6930-8.

7. Fournier D, Hawari J, Halasz A, Streger SH, McClay KR, Masuda H, et al. Aerobic biodegradation of $\mathrm{N}$-nitrosodimethylamine by the propanotroph Rhodococcus ruber ENV425. Applied and environmental microbiology. 2009; 75: 5088-93.

8. Cardini G, Jurtshuk P. The enzymatic hydroxylation of n-octane by Corynebacterium sp. strain 7E1C. The Journal of biological chemistry. 1970; 245: 2789-96. 
9. McKenna EJ, Coon MJ. Enzymatic omega-oxidation. IV. Purification and properties of the omega-hydroxylase of Pseudomonas oleovorans. The Journal of biological chemistry. 1970; 245 : 3882-9.

10. Colby J, Stirling DI, Dalton H. The soluble methane mono-oxygenase of Methylococcus capsulatus (Bath). Its ability to oxygenate $n$-alkanes, $n$-alkenes, ethers, and alicyclic, aromatic and heterocyclic compounds. The Biochemical journal. 1977; 165: 395-402.

11. Kok M, Oldenhuis R, van der Linden MP, Raatjes P, Kingma J, van Lelyveld $\mathrm{PH}$, et al. The Pseudomonas oleovorans alkane hydroxylase gene. Sequence and expression. The Journal of biological chemistry. 1989; 264: 5435-41.

12. Funhoff EG, Bauer U, Garcia-Rubio I, Witholt B, van Beilen JB. CYP153A6, a soluble P450 oxygenase catalyzing terminal-alkane hydroxylation. Journal of bacteriology. 2006; 188: 5220-7.

13. Throne-Holst $\mathrm{M}$, Wentzel A, Ellingsen TE, Kotlar HK, Zotchev SB. Identification of novel genes involved in long-chain n-alkane degradation by Acinetobacter sp. strain DSM 17874. Applied and environmental microbiology. 2007; 73: 3327-32.

14. Stanley SH, Prior SD, Leak DJ, Dalton H. Copper stress underlies the fundamental change in intracellular location of methane mono-oxygenase in methane-oxidizing organisms: Studies in batch and continuous cultures. Biotechnology Letters. 1983; 5: 487-92.

15. Nguyen HH, Elliott SJ, Yip JH, Chan SI. The particulate methane monooxygenase from Methylococcus capsulatus (Bath) is a novel copper-containing three-subunit enzyme. Isolation and characterization. The Journal of biological chemistry. 1998; 273: 7957-66.

16. Elliott SJ, Zhu M, Tso L, Nguyen HHT, Yip JHK, Chan SI. Regio- and Stereoselectivity of Particulate Methane Monooxygenase from Methylococcus capsulatus (Bath). Journal of the American Chemical Society. 1997; 119: 9949-55.

17. Martin KE, Ozsvar J, Coleman NV. SmoXYB1C1Z of Mycobacterium sp. strain NBB4: a soluble methane monooxygenase (sMMO)-like enzyme, active on C2 to $C 4$ alkanes and alkenes. Applied and environmental microbiology. 2014; 80: 5801-6.

18. Burrows KJ, Cornish A, Scott D, Higgins IJ. Substrate Specificities of the Soluble and Particulate Methane Mono-oxygenases of Methylosinus trichosporium OB3b. Microbiology. 1984; 130: 3327-33.
19. Koch DJ, Chen MM, van Beilen JB, Arnold FH. In vivo evolution of butane oxidation by terminal alkane hydroxylases AlkB and CYP153A6. Applied and environmental microbiology. 2009; 75: 337-44.

20. Furuya T, Hirose S, Osanai H, Semba H, Kino K. Identification of the monooxygenase gene clusters responsible for the regioselective oxidation of phenol to hydroquinone in mycobacteria. Applied and environmental microbiology. 2011; 77: 1214-20.

21. Blevins WT, Perry JJ. Metabolism of Propane, $n$-Propylamine, and Propionate by Hydrocarbon-Utilizing Bacteria. Journal of bacteriology. 1972; 112: 513-8.

22. Vestal JR, Perry JJ. Divergent metabolic pathways for propane and propionate utilization by a soil isolate. Journal of bacteriology. 1969; 99: 216-21.

23. Masuda H, McClay K, Steffan RJ, Zylstra GJ. Biodegradation of tetrahydrofuran and 1,4-dioxane by soluble diiron monooxygenase in Pseudonocardia sp. strain ENV478. Journal of molecular microbiology and biotechnology. 2012; 22: 312-6.

24. Mahendra S, Alvarez-Cohen L. Kinetics of 1,4-dioxane biodegradation by monooxygenase-expressing bacteria. Environmental science \& technology. 2006; 40: 5435-42.

25. Masuda H, McClay K, Steffan RJ, Zylstra GJ. Characterization of three propane-inducible oxygenases in Mycobacterium sp. strain ENV421. Letters in applied microbiology. 2012; 55: 175-81.

26. Aziz RK, Bartels D, Best AA, DeJongh M, Disz T, Edwards RA, et al. The RAST Server: Rapid Annotations using Subsystems Technology. BMC genomics. 2008; 9: 75.

27. Notomista E, Lahm A, Di Donato A, Tramontano A. Evolution of bacterial and archaeal multicomponent monooxygenases. J Mol Evol. 2003; 56: 435-45.

28. Sluis MK, Small FJ, Allen JR, Ensign SA. Involvement of an ATP-dependent carboxylase in a CO2-dependent pathway of acetone metabolism by Xanthobacter strain Py2. Journal of bacteriology. 1996; 178: 4020-6.

29. Kotani T, Yurimoto H, Kato N, Sakai Y. Novel acetone metabolism in a propane-utilizing bacterium, Gordonia sp. strain TY-5. Journal of bacteriology. 2007; 189: 886-93.

30. Taylor DG, Trudgill PW, Cripps RE, Harris PR. The Microbial Metabolism of Acetone. Microbiology. 1980; 118: 159-70. 